\title{
La sal de las finanzas. Peñón Blanco en la primera mitad del siglo XIX
}

Eduardo Flores Clair DEH-INAH

Preliminar

$\mathrm{E}$ n este trabajo pretendemos abordar la privatización de las salinas en la primera mitad del siglo XIX, poniendo mayor énfasis en las lagunas de Peñón Blanco, San Luis Potosí. Para cumplir con tal propósito, nos parece necesario hacer un largo recorrido teniendo en cuenta los siguientes elementos: la situación que prevalecía en las salinas reales en los últimos años coloniales, la política de los gobiernos independientes y la recaudación de las rentas, así como la relación de la minería con la producción de la sal, y los problemas que se generaron a nivel regional con la privatización de las salinas de Peñón Blanco.
Descle tiempos muy remotos, la producción de sal ha tenido una gran importancia en la historia de la humanidad. ${ }^{1}$ La sal se ha destacado por su estrecha relación con una amplia gama de industrias, actividades y ritos; a lo largo del siglo XIX cobró una gran importancia en la curtiduría, fabricación de jabón, químicos, vidrio, explosivos y cerámica, al igual que en las fábricas textiles, en las haciendas ganaderas y en la agricultura. En la cocina resultaba insustituible y se empleaba en abundancia en las empresas dedicadas a elaborar alimentos. Cabe destacar que la minería de la plata consumía enormes volúmenes.

1 Multhauf, Legado, 1985. 


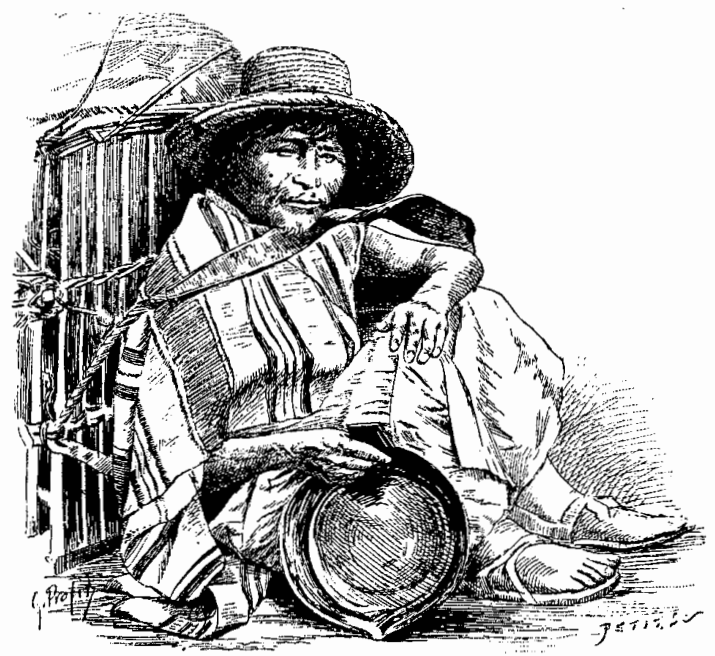

Desde el siglo XVI, la sal ocupó un lugar destacado en el beneficio de los minerales argentíferos. Los españoles introdujeron el método de amalgamación en frío; dicho sistema armonizó con los minerales novohispanos y fue empleado a lo largo de cuatro siglos. El proceso principiaba con la molienda de los minerales que previamente eran sacados de las minas; las piedras se trituraban hasta obtener un polvo fino; en seguida, la masa era mezclada con sal, mercurio y greta, con el fin de formar sulfuros y recoger el metal precioso con mayor facilidad. Por esta razón, la sal fue un insumo básico de la industria minera. ${ }^{2}$

Al igual que en otras regiones del

${ }^{2}$ Carreón, Curso, 1903; Ramírez, "Conferencias", 1876-1877. mundo, la corona española hizo de la sal una renta pública en la Nueva España. Después de la conquista, el gobierno español intervino por periodos interrumpidos en la producción y distribución de la sal. Muy pronto, en 1580 , la corona dispuso una serie de normas que regularon las relaciones entre productores -pueblos de indios- $y$ consumidores. ${ }^{3}$ Dicha legislación abarcó los ramos de propiedad, producción, transporte y comercio.

Pero la realidad novohispana condicionó la aplicación de las leyes espanolas; los gobiernos virreinales tuvieron que fusionar las ancestrales costumbres prehispánicas con los nuevos códigos.

3 Ventura Beleña, Recopilación, 1981, vol. I, pp. 106-110 y 310-311. 
En muchos lugares, apunta Ursula Ewald, la producción indígena de sal sobrevivió en pequeña escala, mientras en el norte o en la costa, las grandes salinas a menudo cayeron bajo la administración española. ${ }^{4}$

Por este hecho no resulta extraño que la corona enfrentara una serie de tropiezos para conciliar los intereses involucrados en la propiedad, explotación, transporte, distribución, comercio y consumo de sal. Tal vez por ello, la corona aplicó un conjunto de mediaciones casuísticas y prefirió seguir una política flexible, aunque no por ello menos compleja: monopolizando, arrendando y otorgando el libre usufructo de las salinas.

Años más tarde, como en otros ramos de la administración, la política borbónica introdujo una serie de mecanismos innovadores para controlar y centralizar las rentas de las salinas. José de Gálvez, el famoso visitador, recorrió, durante su estadía en Nueva España, gran parte del territorio y visitó las principales salinas del reino. Como un moderno evangelizador fue modificando las condiciones, los precios, las formas de trabajo, los impuestos y los abusos de los oficiales reales en las salinas. A su paso, encontró una enorme riqueza a lo largo de las costas y en las provincias de tierra adentro. Pero a Gálvez le preocupaba que la corona tuviera ingresos exiguos por la renta de la sal.

Después de levantar datos y pedir informes, Gálvez calculó que en

${ }^{4}$ Ewald, Mexican, 1985, p. 17. la Nueva España se consumían anualmente 250000 cargas de sal; en consecuencia, la recaudación fiscal debía ser considerable. En su investigación, Gálvez econtró que las salinas estaban distribuidas en muchas manos, algunas eran patrimonio de particulares, corporaciones y comunidades indígenas; otras pertenecían a la Real Hacienda, que las administraba por su cuenta o las arrendaba. $Y$ con un espíritu más liberal, las Ordenanzas de Minería (1783) concedieron el derecho de adquirir en propiedad las salinas de nuevo descubrimiento mediante el denuncio, es decir, de la misma manera como se obtenían las minas. 5

Por los escritos de Gálvez, podemos constatar que le interesaba renovar el orden en el ramo de la sal; puso especial cuidado en ciertos factores, como por ejemplo: estimular la producción, reducir el precio, abolir impuestos, asegurar el abasto a la minería, terminar con los vicios administrativos y proteger el uso doméstico de los pueblos de indios. Para llevar a cabo tales acciones, Gálvez diseñó diversas estrategias, con el fin de atacar los fuertes privilegios que se habían creado a lo largo del tiempo y sanear la administración colonial. Todas estas medidas iban encaminadas a brindarle a la corona mayores recursos.

Siguiendo este interés, las autoridades coloniales establecieron un es. tanco en la ciudad de Veracruz con la producción salina de Campeche y Yucatán; sin embargo, el estanco tuvo una historia desafortunada (como en

\footnotetext{
SOrdenanzas, 1961.
} 
tiempos pasados). ${ }^{6}$ En 1774 , a pesar de las múltiples protestas de los vecinos y oficiales reales de Tampico y Altamira, se erigió el estanco veracruzano. En esa ocasión, los comerciantes de Campeche aprovecharon la oportunidad y saturaron el estanco con sal barata, que adquirían a bajos precios en las provincias de Caracas, Guaranao y Monte-Christi. El estanco sólo resistió veintiseis meses hasta que, en febrero de 1776 , las autoridades ordenaron el finiquito y autorizador el comercio libre de la sal.

Sin tener en cuenta el descalabro financiero, una década después, la corona insistió en la instauración del estanco veracruzano. En ese episodio, se impuso dicha medida a pesar de que los dueños de las embarcaciones que transportaban la sal y los propietarios de las pesquerías de Yucatán presentaron una fuerte oposición por los perjuicios que les acusaba. El estanco sólo funcionó poco tiempo y, una vez más, los oficiales reales vieron frustadas sus esperanzas de obtener cuantiosas utilidades. En 1790, el virrey decretó que se extinguiera "el estanco de sal de Veracruz, dejando a la provincia de Yucatán y vecinos de Campeche, la libertad que tenían antes de conducir a dicho puerto en la cantidad y tiempos que conviniere a los interesados toda la sal". ${ }^{7}$

\footnotetext{
${ }^{6}$ A fines del siglo xvi y principios del xvi, el gobierno colonial intentó crear un estanco de la sal, pero por diversas causas fracaso. Para una mayor información véase Sarabia, "Estanco", 1978 , pp. $379-405$.

7 Fonseca y Urrutia, Historia, 1845, vol. N, pp. 63-73.
}

Las salinas del pacífico norte tuvieron una historia distinta. En 1768 Antonio Dávalos dio por terminado su contrato de arrendamiento de las salinas de Zapotillo, hoy estado de Jalisco. En su lugar, Gálvez propuso arrendar los "ranchos", (terrenos para secar la sal) a un amplio grupo de pequeños productores independientes. Estos debían pagar una cuota fija de 10 pesos anuales y vender la carga de sal a 6 reales, misma que la Real Hacienda remataba a 9 reales. Esta nueva forma de explotación de las salinas parecía un negocio redituable, además de no lesionar los intereses de otros pueblos, como los pescadores. Dicho arrendamiento se estableció en todas las salinas asentadas a lo largo de la costa entre Colima y Mazatlán.

El extenso territorio fue poblado por cerca de 800 pequeños rentistas que emprendieron la tarea de extraer la sal. Sin embargo, la producción disminuyó en la zona debido a que los pequeños salineros fueron incapaces de abastecer la demanda, que provenía principalmente de los centros mineros. El arrendamiento de ranchos y el precio de la sal no compensó en mucho las antiguas rentas del erario. Por este motivo, a principios de 1780 , José Faustino Ruiz contador del ramo planteó ante las autoridades un proyecto redituable para que las salinas fueran administradas por la Real Hacienda.

Meses más tarde, en diciembre de 1781 , "el superior gobierno" determinó poner en práctica el proyecto de Ruiz, quien calculaba producir más de 30000 cargas anuales de sal y obtener fabulosos ingresos para el erario. 
De esta manera, la Real Hacienda administró por su cuenta al resto de las salinas del Pacífico norte. Pero años después, las cuentas reales demostraron que había sido un error costoso, pues en el periodo de 1782-1788, el erario sólo recibió, en promedio, 11113 pesos anuales; en cambio, durante $1775-1781$ con el arrendamiento de los ranchos, captó 21496 pesos. Por lo tanto, la Real Hacienda dejó de percibir más de 10000 pesos anualmente. Ante tal hecho, a mediados de 1790 , se suspendió la administración real de las salinas y los pequeños productores de nueva cuenta arrendaron los ranchos.

Más al sur, las salinas de Tehuantepec vivieron una situación distinta. En 1778, Miguel Alarcón, administrador de tabacos de ese partido, denunció nueve lagunas que se extendían por la costa oaxaqueña; antiguamente, los curas del orden de Santo Domingo habían administrado dichas salinas y su último poseedor había sido Juan de Zúñiga y Cortés, quien las había adquirido por medio de una merced real. Alarcón elaboró diversos informes para convencer a las autoridades de que las salinas de Tehuantepec podian llegar a ser un negocio bonancible.

Poco tiempo después, en 1782 , las autoridades coloniales designaron a Miguel Alarcón como administrador de las salinas de Tehuantepec. Alarcón tuvo que enfrentar grandes obstáculos para poner en funcionamiento las salinas; acordó con los caciques locales el abasto de mano de obra para cosechar la sal, se comprometió a pagar en efectivo y a permitirles recoger toda la sal necesaria para su uso doméstico. Es importante señalar que los salineros se beneficiaban con la contratación de indígenas locales. La cosecha de sal era muy corta, se realizaba durante los meses de secas, y la mano de obra esclava elevaba mucho el costo de producción, por lo cual resultaba más redituable contratar indígenas por cortas temporadas.

En 1793, el virrey Matías de Gálvez expidió un reglamento para las salinas de Tehuantepec, cuyo amplio capitulado sancionó una serie de problemas, entre los que destacan los mecanismos contra la corrupción de los oficiales reales y el contrabando. Para Miguel Alarcón, antiguo administrador, dichos problemas eran los mayores obstáculos que impedian el desarrollo de la salinas de Tehuantepec.

La experiencia ha enseñado, señala el reglamento, que mientras los jefes principales descansan sobre las confianzas, han faltado a ella no pocos subalternos sobornados del vil cohecho; por lo que el administrador estará siempre vigilante sobre la conducta de todos. Más adelante se sancionó que los denunciantes $o$ aprehensores tienen derecho a la cuarta parte de la sal que cojan, así como también lo tiene a la otra cuarta parte el administrador cuando por sí o sus dependientes encuentren el contrabando. 8

Todo parece indicar que las medidas tomadas en el caso de las salinas de Tehuantepec tuvieron un funcionamiento efectivo, pues ese tipo de administración continuó hasta bien entrado el siglo XIX.

8 Ibid. pp. 111-112. 
En la otra costa, José de Galvéz realizó muchas diligencias con el fin de que la Hacienda Real administrara las salinas de Nuevo Santander, Tamaulipas, pero sus esfuerzos fueron infructuosos. En 1772, dichas salinas continuaban explotándose por su antiguo arrendador, Melchor de Noriega, quien pagaba 3000 pesos anuales. Sin embargo, por largos periodos, la Hacienda Real no tuvo noticia de la administración de dichas salinas. En 1787 , a solicitud de las autoridades, Noriega pagó el arrendamiento que adeudaba desde hacía diez años. Dos años después, el Tribunal de Cuentas de San Luis Potosí mencionó que no tenía información suficiente, pero "creían que el arrendamiento continuaba".

Una de las salinas más importantes, Peñón Blanco, San Luis Potosí, estaba arrendada al conde de Casafiel, el cual pagaba la cuantiosa suma de 35500 pesos al año por explotarlas. Sin embargo, poco antes de que terminara el contrato de arrendamiento en 1778, Juan de Aranda, contador oficial de Zacatecas, presentó un plan para que la Real Hacienda tomara la administración de las salinas. Aranda pensaba que las salinas de Peñón Blanco proporcionarían una renta anual superior a los 90000 pesos. Por tal motivo, el contrato de arrendamiento se canceló y Aranda fue nombrado administrador de las salinas. Desafortunadamente, las perspectivas halagadoras del erario no se cumplieron, es más, no alcanzaron las cifras del antiguo rentista. 9

9 Ibid. p. 87.
A simple vista, una primera conclusión que podemos sacar de las reformas borbónicas aplicadas al ramo de la sal, es que fracasaron. Los ejemplos regionales demuestran que las autoridades fueron incapaces de aumentar los caudales del erario. Pero resulta significativo notar que la política colonial fue diversa y buscó nuevas formas de control social: desde un régimen despótico como la administración real y el estanco, pasando por una forma más flexible de arrendamiento a particulares, hasta una línea de mayor participación y concertación, como en el caso de arrendamiento a pequeños productores.

En este sentido, Clara Lida señaló que

el arrendatario, además de ocuparse de la producción y distribución de la sal y de pagar el diezmo real anual, contraía ciertas obligaciones administrativas, respecto a la población indígena de la zona y militares, de "regir y gobernar la gente de guerra cuando se ofrezca reprimir a los indios enemigos de sus insultos y barbaridades". 10

Por lo tanto el arrendatario no sólo jugaba un papel económico en la localidad, sino que se encargaba de regular el orden social a nivel regional.

Las diversas regiones salineras experimentaron con diferentes formas de trabajo, abrieron circuitos comerciales e incrementaron fuertemente su producción para satisfacer a un mercado en expansión. No podemos pa-

${ }^{10}$ Lida, "Sobre", 1965, p. 684. 


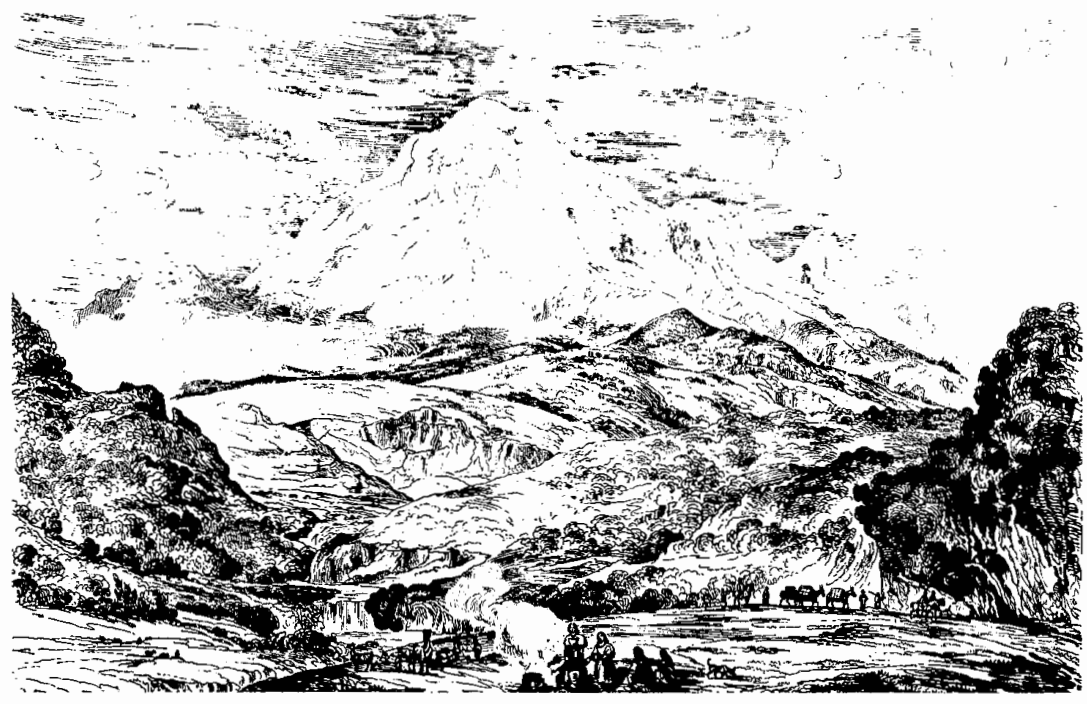

sar por alto que durante esa época, la minería disfrutó de un acelerado crecimiento y no padeció por el abasto de sal. En otras palabras, mientras el erario perdió parte de sus rentas, el sector minero se benefició por la política de fomento estatal de la producción, control de precio y distribución de la sal. $Y$ por lo tanto, podríamos considerar que las reformas aplicadas en las salinas, eran un eslabón más de la política global borbónica para apoyar al sector minero. Como afirma John H. Coatsworth,

la industria minera de fines de la colonia enfrentaba problemas tan serios que sólo logró sobrevivir recurriendo al erario público y atrayendo recursos de otros sectores. 11

11 Coatsworth, "Industria", 1990, p. 58.

\section{LA HERENCIA COLONIAL}

Poco sabemos sobre la situación que prevaleció en las salinas durante la revolución de independencia. Pero por los papeles que se conservan en el antiguo Tribunal de Minería, podemos intuir que los mineros no tuvieron grandes problemas para abastecerse de sal y quizá la población tampoco. En cambio la escasez de mercurio, importado de España, se convirtió en el talón de Aquiles de la producción minera. Este insumo era de tal manera imprescindible que se abolió el monopolio, con lo cual los particulares tuvieron el derecho de explotar los yacimientos de mercurio en el territorio y comerciar libremente con otros países. Sin embargo, el Estado siguió manteniendo el control así como 


\section{SECUENCIG}

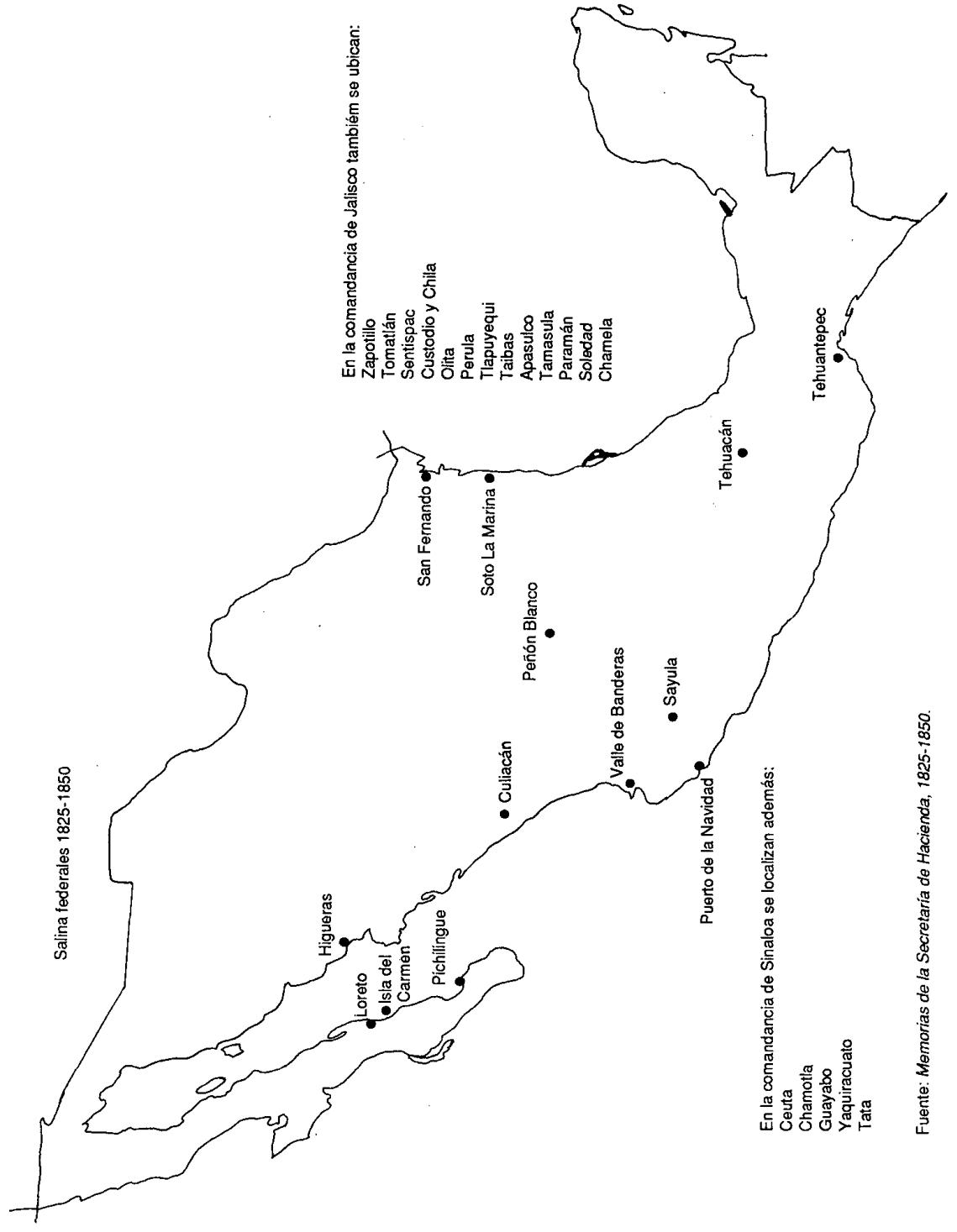


la propiedad de las salinas más productivas e importantes del país. ${ }^{12}$

Las salinas de la federación tenían una distribución geográfica que abarcaba gran parte del territorio nacional, como podemos ver en el mapa.

Por desgracia, sólo conocemos el nombre y la ubicación estatal de muchas de ellas, pero carecemos de datos sobre la producción y administración de la mayoría de estos yacimientos salinos. Este vacío de información lo compartimos con algunos funcionarios del Ministerio de Hacienda, quienes en 1826 declararon haber descubierto en los estados norteños un buen número de salinas que pertenecían a la federación. Además, afirmaron que los habitantes locales "las creían propiedad común" y enviaban sus atajos de mulas para recoger la sal. ${ }^{13}$

En realidad, las salinas estaban abandonadas en su gran mayoría y, aunque se hicieron grandes esfuerzos, esa situación no cambio en poco tiempo. En 1835, el ministro de Hacienda decía que en "algunas salinas ignora el gobierno la causa que procede, y aunque ha tratado de investigar para hacerlo presente a las Cámaras, la premura del tiempo no lo ha permitido". 14

Es importante tener en cuenta las medidas políticas de los gobiernos independientes respecto al ramo de la sal, para evaluar con mayor precisión la importancia nacional y regional de este sector. Por el momento, resulta reiterativo decir que el país vivió una gran turbulencia política en las pri-

12 Herrera, "Busca", 1988, pp. 159-178.

13 Memoria.. Hacienda, 1826, pp. 32-34.

14 Memoria.. Hacienda, 1835, p. 9. meras décadas de vida independiente, que dicho desorden se reflejó en graves problemas para administrar los bienes de la federación, como en el caso de las salinas.

La política de los gobiernos independientes relativa al ramo de la sal, estuvo estrechamente relacionada con la bancarrota perpetua de la hacienda pública y con la rehabilitación de la industria minera. En 1823, el ministro de Hacienda, Antonio de Medina, expuso ante el Congreso que la grave contracción del erario nacional era producto de las necesidades locales, el desorden de doce años de revolución y la extinción y bajas que sufrieron algunos ramos fiscales. ${ }^{15}$

La triste historia de la hacienda pública refleja cuando menos, dos rasgos distintivos de las condiciones que prevalecieron en las salinas estatales al despuntar el siglo XIX. Primero, la grave contracción de los ingresos y la merma en la capacidad y credibilidad para recaudación fiscal. Segundo, el desorden que dejó la guerra y la drástica caída de la producción minera, que afectó el desarrollo de las salinas considerablemente.

Por esos años, en diversas instancias se discutió la posibilidad de que las rentas de la sal pasaran a formar parte de los ingresos de los estados. El Congreso de Jalisco, opinó en 1824 que el estanco del tabaco y de la sal no les beneficiaba, por lo cual solicitó a la federación les cediera los ingresos que generaban dichos estancos. ${ }^{16} \mathrm{El} \mathrm{Con-}$ greso general discutió con profundi- 
dad la conveniencia de ceder las salinas a los estados de la federación, pero no se avanzó mucho en este renglón. Sólo de manera excepcional, el gobierno concedió a los vecinos de Tamaulipas el derecho de explotación de las salinas de Nuevo Santander por ocho años; dicho derecho fue renovado en 1833 por diez años más. ${ }^{17}$

Ahora bien, en varias instancias de gobierno continuó la polémica sobre el problema de los monopolios o rentas estancadas; en dichos debates, los librecambistas, según su espíritu ortodoxo, no perdian la oportunidad de impugnar dichos privilegios. Sin embargo, la realidad los hacia ir en contra de sus principios y, en repetidas ocasiones, no les quedó más remedio que avalar y firmar la enajenación de las rentas nacionales.

A finales de 1824, el Congreso general emitió varias leyes con el fin de ordenar las cuentas nacionales y allegarse recursos para cubrir el déficit presupuestal. El gobierno ordenó arrendar las salinas de la federación en subasta pública, al mejor postor y por el tiempo que consideraran conveniente. Asimismo, se acordó reducir el $25 \%$ de los impuestos de las salinas particulares y arrendar su recaudación. También se exigió "vender las sales bajo las reglas adoptadas por la hacienda pública en beneficio de la minería y en una

17 Decreto 437, "Arreglo de la administración de la hacienda pública", 16 noviembre 1824; y "Gracia concedida a todos los criaderos de sal del territorio del estado de Tamaulipas", 30 mayo 1833 . cuarta menos del valor a que aquella las vendía". ${ }^{18}$

Este conjunto de medidas no tuvo el éxito que se esperaba; en muchos lugares no se presentaron los postores y se declararon desiertas las subastas; en otros sitios no se corrió con mejor suerte, los postores ofrecieron cantidades tan pequeñas que no fue posible aceptarlas. Por ejemplo, en el caso de Tomatlán y Valle de Banderas, los comisarios decidieron arrendar los ranchos para "no perder la presente zafra"; en las salinas de Zapotillo propusieron que los pobladores se quedaran con la mitad de la cosecha para pagar sus servicios y la otra mitad fuera entregada a la hacienda pública. Vicente Michel pidió cinco años de gracia en el arrendamiento de las salinas de Chamela y se comprometió a abrir pozos y caminos. En el caso de Peñón Blanco, un postor ofreció 14000 pesos, pero no se aceptó la oferta porque el presupuesto de esa salina era de 24000 pesos. En este primer intento de arrendamiento, el erario obtuvo una escasa liquidez; sólo se arrendaron las salinas de Ceuta por 1333 pesos, Chametla por 400 pesos e Higueras por 465 pesos. ${ }^{19}$

A pesar de todos los problemas, poco a poco, las salinas se fueron arrendando; los contratos concedieron grandes ventajas a los asentistas e incluyeron algunas cláusulas para regular el precio y el crédito a los mineros. Cabe agregar que el gobierno mantuvo por su cuenta la adminis-

$18 \mathrm{Ibid}$.

19 Manifiesto, 1827 , pp. 32-34. 


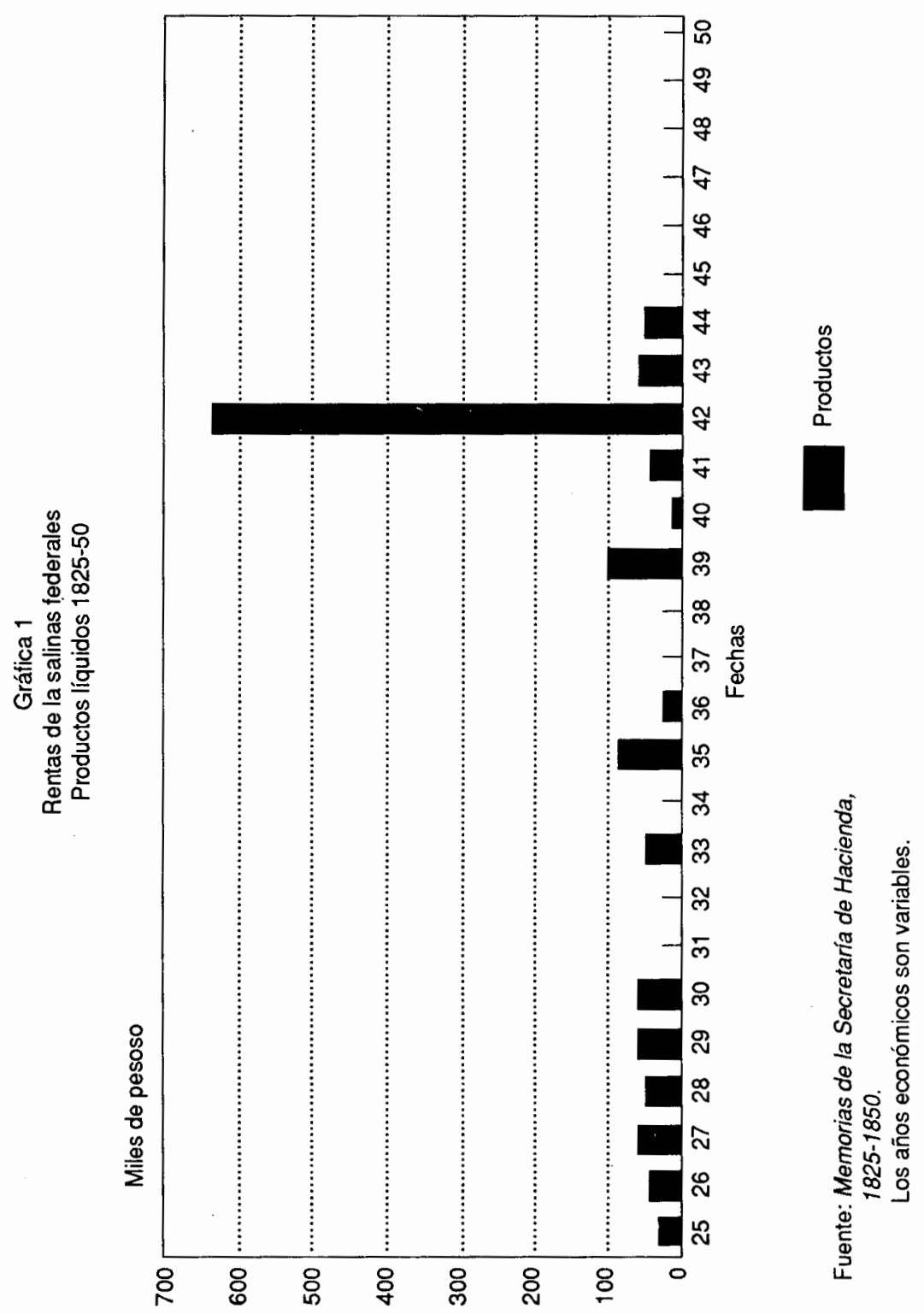


tración y explotación de las salinas de Tehuantepec hasta 1843.20

Años después, como todos sabemos, la crisis del erario se agudizó. En 1838, el Congreso general autorizó al ejecutivo a vender las salinas. En ese momento apareció de nueva cuenta la política de fomento a la minería, pues se puso como condición que "el comprador siga vendiendo a las minas la sal-grano y la sal-tierra, con los plazos y a precios a que hasta aquí se les han dado". ${ }^{21}$ A partir de este momento se abrió un proceso de privatización

20 El ex ministro de Hacienda -Javier Echeverría-adquirio estas salinas por la ridícula cifra de 9000 pesos.

21 Ley 2000, "Autorización al gobierno para que enajene las salinas de Peñón Blanco, $y$ el edificio de la ex inquisición", 22 noviembre 1838. de todas las salinas federales; no obstante, el gobierno enfrentó una serie de problemas para cumplir con este mandato.

Un indicador que resulta imprescindible para analizar la política de los gobiernos independientes, es sin duda la recaudación fiscal. Sin embargo, al realizar un recuento estadístico de las rentas del ramo de la sal a través de las Memorias de la Secretaría de Hacienda, nos enfrentamos con una serie de problemas que nos impidieron crear una serie de datos continua y homogénea. En la gráfica 1, presentamos la recaudación líquida de las salinas de la federación entre 1825 y 1850 .

En ella podemos ver tres periodos muy definidos: en los primeros años se nota un incremento que co-

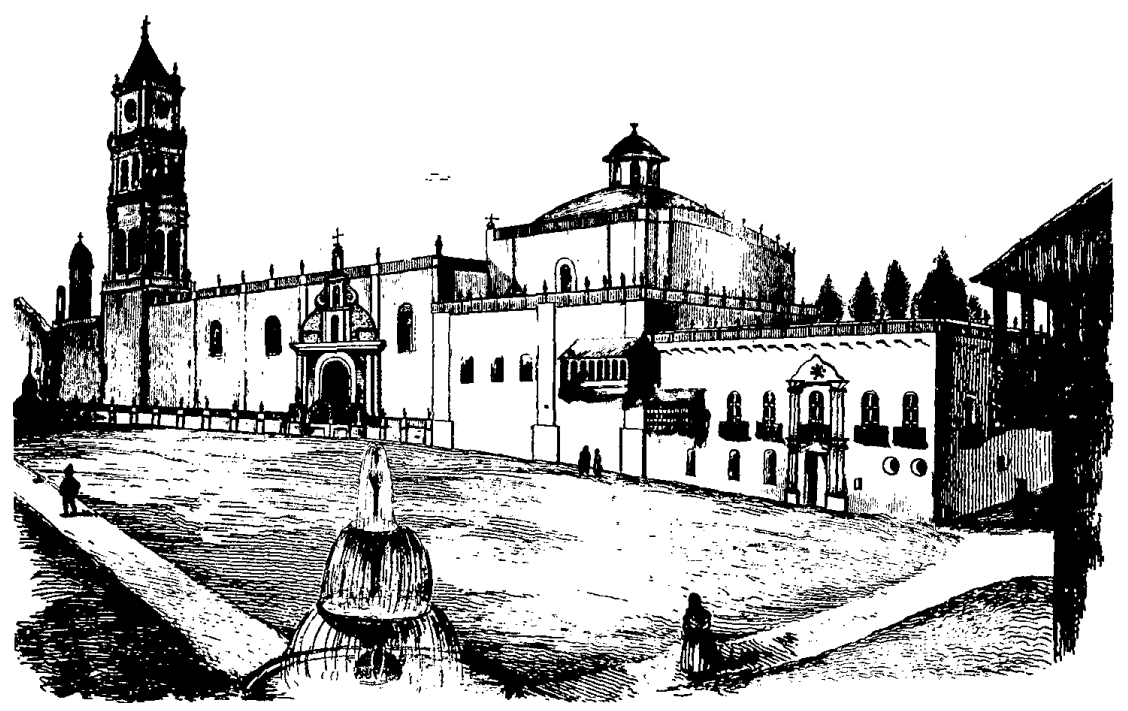


rresponde al arrendamiento progresivo de un gran número de salinas; dicha tendencia se rompe quince años después, con el remate de las salinas más importantes: 1839 Sayula, 1842 Peñón Blanco, Jalisco, Sinaloa. Una vez realizada la venta, podemos constatar un deterioro progresivo hasta lle. gar al punto de recaudar una cifra insignificante. $^{22}$

Pocas son las conclusiones a las que podemos llegar a partir de este grupo de datos desagregados e incompletos. En primer lugar, si se comparan los ingresos de la sal con otro tipo de rentas estancadas, podemos constatar que son muy pobres. El monto de la recaudación nos hace suponer que, a los distintos gobiernos, jamás les interesó impulsar la administración de dichos bienes con una lógica del capital. Podemos asegurar que no buscaban la ganancia en la producción sino, más bien, abastecer a un mercado cautivo y subvencionado como era el minero.

Desde las primeras décadas del México independiente, los gobiernos en turno pretendieron, en menor o mayor medida, liberar los bienes nacionales. Es decir, ceder el dominio a los particulares, auque el Estado no quería perder el derecho a intervenir y regular la producción y distribución de los bienes. La privatización de las salinas o de otros bienes nacionales, abrió un proceso de transición, en el cual se enfrentaron dos concepciones de Estado: la idea de preservar ciertos privilegios patrimoniales, frente a la libre concurrencia. En este tránsito par-

22 Las cifras se consignan en el apéndice I. ticiparon muchos grupos de interés a nivel nacional y regional.

Los bienes nacionales podían ser usufructuados por el Estado central, pero los distintos grupos regionales reclamaban una participación en los beneficios de dichos bienes, por el simple hecho de estar localizados en su ámbito territorial.

\section{PRODUCCIÓN SALINA Y MINERÍA}

A lo largo del texto hemos insistido en la política estatal de fomento a la industria minera; como se ha mencionado, dicha actividad recibió cliversos estímulos por su lugar predominante en la economía y con el fin de animar a otros sectores que se encontraban eslabonados por lazos comerciales. Antes de seguir adelante, conviene tener presente que en la primera mitad del siglo XIX, por disposición legal, la producción minera tenía que refinarse (o beneficiarse) en territorio nacional. ${ }^{23}$ Por ello, las compañías mineras tenían la necesidad de comprar inmensos volúmenes de sal para refinar sus minerales.

Pero, en realidad, icuánta sal consumía la industria minera? Ésta es una pregunta muy compleja que implica un conjunto de problemas de diversa índole. Más que contestarla, intentaremos describir los fenómenos que la rodean. En primer lugar, no tenemos por desgracia un índice con-

${ }^{23}$ A este respecto cabe advertir que en 1869 , el gobierno permitió la exportación de minerales en bruto, o piedra mineral; sin embargo, este negocio resultó incosteable para las compañías. 
fiable de la producción minera, aunque poseemos una valiosa estadística de acuñación. Es decir, para construir un índice completo de la producción, falta agregar la parte correspondiente al consumo de la orfebrería nacional, atesoramiento particular y contrabando, cifras que desconocemos hasta ahora. A pesar de este grave problema, el índice de acuñación nos muestra la tendencia general y relativa que siguió la producción minera. En segundo lugar, el consumo de sal estaba directamente relacionado con la ley de los minerales, es decir, que entre más ricos, mayor era la cantidad de sal que se consumía.

Los minerales argentíferos que se extraían de las minas tenían una determinada cantidad de plata y oro; en lenguaje técnico, ésta es la ley de los minerales. Un cálculo de finales del siglo pasado nos dice que, para una tonelada de mineral, con una ley de 1 a 1.7 kilogramos, se solía ocupar entre 30 y $50 \mathrm{~kg}$ de sal. Para leyes mayores de $1.7 \mathrm{~kg}$ se utilizaban $2 \mathrm{~kg}$ de sal para beneficiar, cada cien gramos de plata. Es decir, si una tonelada de mineral tenía una ley de $3 \mathrm{~kg}$, se empleaban aproximadamente $60 \mathrm{~kg}$ de sal. ${ }^{24}$

Las haciendas de beneficio habían acumulado experiencia y tenían sus propias costumbres en la metalurgia; algunos mineros consumían una mayor cantidad de sal en comparación con otros. Otros factores que hacian variar el consumo de la sal eran las características físicas, la composición química de los minerales y la época del año en que se realizaba el beneficio. Es

24 Véase El Minero Mexicano, vol. vil, núm. 38,7 noviembre 1881 . importante agregar que, las compañías mineras perdían al año por almacenar la sal entre 5 y $10 \%$ de sus existencias. La cantidad exacta de sal que se consumía para producir un gramo de plata es una cifra utópica.

Proponemos una hipótesis estadística para estimar la cantidad de sal consumida en la minería partiendo del cálculo de Adolf Soetbeer sobre producción. Él asegura que entre 1821 y 1830 se produjeron 2657.76 toneladas de plata y oro. ${ }^{25}$ En segundo lugar, hay que tener en cuenta que la mayoría de las compañías extraían minerales pobres, los cuales tenían una ley entre 8 y 15 marcos por montón; por esta razón proponemos una ley media de 10 marcos por montón, lo que equivale a $.600 \mathrm{~kg}$ por tonelada. Por lo tanto, si se utilizaban $30 \mathrm{~kg}$ de sal por cada tonelada, resultaría que se habrían necesitado 47839.68 toneladas aproximadamente para beneficiar toda la producción. En otras palabras, según nuestro cálculo, la minería habría consumido anualmente cerca de 5000 toneladas de sal entre $\mathbf{1 8 2 1}$ y 1830.

Este cálculo meramente especulativo, quizá nos pueda ser más útil cuando tengamos una serie larga del consumo de sal de alguna compañía minera para compararlo; por ahora, sólo nos lleva a imaginarnos una producción muy alta. Además, si agregamos la sal consumida en la dieta de los habitantes y la requerida por otras actividades económicas, tenemos una cifra estratosférica. ${ }^{26}$

25 Flores Clair, Estadísticas, 1985, p. 15.

26 Durante el segundo imperio, Thomas Hindman y Richard L. Maury aseguraron que "cada habitante del imperio consumía anual- 


\section{SECUENCIA}

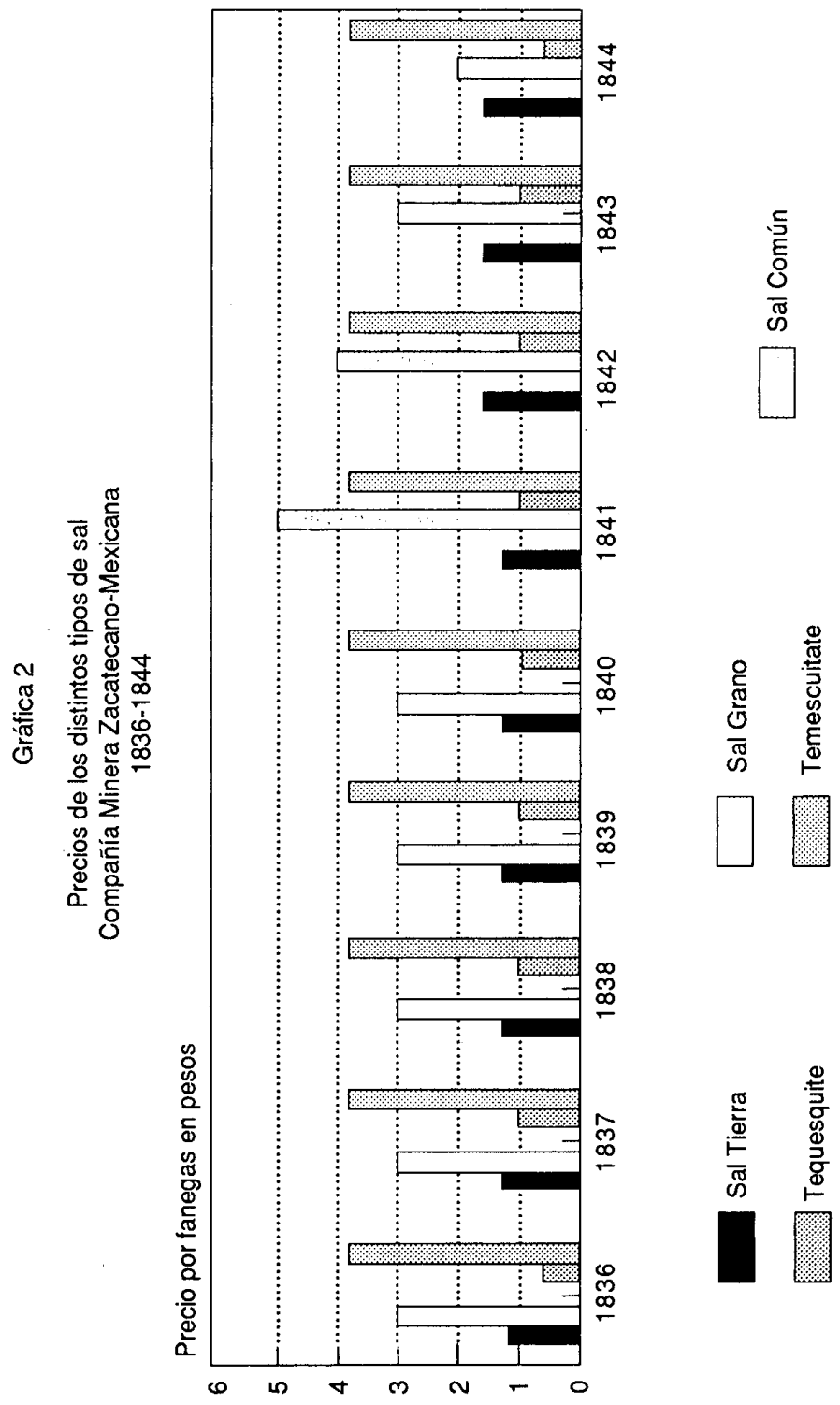


Estos hechos nos describen un mercado difícil de satisfacer, por los inmensos volúmenes que se debian alcanzar en la producción y por las grandes distancias que había que recorrer entre las salinas y los centros de consumo. Ia situación salinera nos remite a un mercado muy vulnerable. Robert Randall afirmó que, para satisfacer las necesidades de las minas de Real del Monte, la sal se traía

desde Campeche, por el Golfo y los puertos de Veracruz y Tampico, o por tierra, desde el estado occidental de Colima. Su costo en el centro minero fue, la mayor parte del tiempo, [18241849] de $\$ 1.06$ a $\$ 1.63$ la arroba, pero en agosto de 1835 la empresa se vio obligada a pagar casi $\$ 2.50$ por arroba de un cargamento procedente de Yucatán. ${ }^{27}$

Por los distintos informes de las compañías mineras, podemos saber que los precios tendían a fluctuar y que los consumidores estaban en ma. nos de los comerciantes, fleteros y especuladores, sin olvidar que, de vez en cuando, la madre naturaleza les jugaba rudo y echaba a perder las cosechas, por lo cual, la sal aumentaba de precio considerablemente. En la gráfica 2, podemos apreciar las fluctuaciones de precios y las distintas calidades de la sal que compraba la Compañía Zacatecano-Mexicana. Ésta gastaba en promedio poco más de

mente una arroba (25 libras), más o menos". "Proyecto para formar la Compañía Salinera Imperial Mexicana", Archivo General de la Nación (AGN), Minas y petróleo: caja 46, exp. 46, s/f.

27 Randall, Real, 1977, p. 181.
100000 pesos anuales para abastecerse de sal. ${ }^{28}$

Esta empresa no era excepcional; la Compañía Real del Monte y Pachuca durante 1860 y 1861 que estaba en bonanza compró sal por más de 330000 pesos. Para tener una idea más precisa sobre la importancia de la sal respecto al gasto de las compañías mineras, presentamos la gráfica 3. Como vemos, la sal ocupaba el segundo gasto más importante de la Compañía Real del Monte y Pachuca, sólo detrás de la madera, y por encima del azogue.

Las compañías mineras invirticron fuertes capitales y aportaron sus ilustres ingenieros para buscar la manera de sustituir el método de bene. ficio de patio; sin embargo, los esfuerzos fueron vanos. La minería argentífera creó una fuerte dependencia de los centros salineros; anualmente, las compañías desembolsaban grandes cantidades para la compra de sal y el pago de los fletes. Dicha situación perduró hasta finales del siglo pasado; el descubrimiento del método de beneficio por cianuración transformó el sistema productivo minero y creó una nueva red de relaciones comerciales con otros sectores. La sal pasó a dominio de otras actividades e industrias.

\section{SAI. Y ESPECULADORES}

Vale la pena hacer un paréntesis y preguntarse ecómo se hacían los negocios con el gobierno?, ¿cómo se arrenda-

28 Véanse los informes de la ZacatecanoMexicana de los afos de 1838, 1839, 1841 y 1842. 


\section{Gráfica 3 \\ Distribución del gasto
Compañía Real del Monte y
Pachuca 1860-1861}

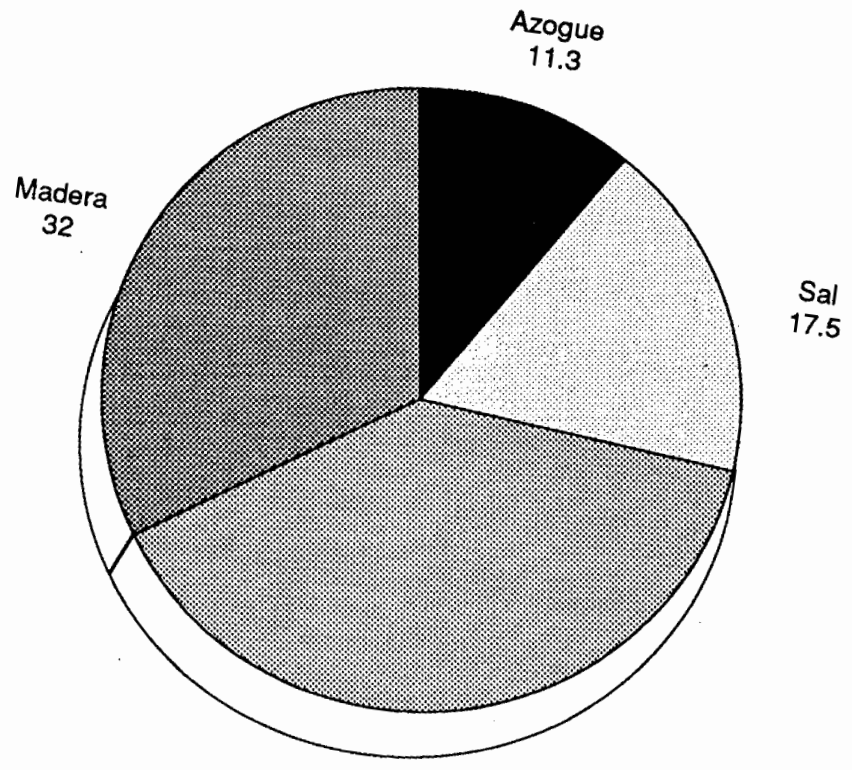

Otros

39.2

Burkart, "Memoria", 1861.

LA SAL DE LAS FINANZAS 
ban o vendian los bienes nacionales?, ¿cuáles eran los grupos que participaban en esas transacciones?, ¿cómo se formaban las alianzas entre los especuladores y los funcionarios públicos?, ide qué manera la privatización de los bienes nacionales ayudó a formar grupos económicos y políticos a nivel regional?

Las respuestas no pueden ser simples por la complejidad histórica de esos años. En los estudios de Rosa Ma. Meyer se demuestra con una gran claridad, que el poder económico se encontraba estrechamente vinculado con el poder político. Los inversionistas tenían la necesidad de poseer o comprar influencias políticas para conseguir el éxito económico en sus empresas. De manera coyuntural,

los negocios preferidos por estos grandes comerciantes eran los que se relacionaban con los préstamos al gobierno. La década que va de 1830 a 1840 fue la época de oro de los agiotistas. 29

A este tipo de fenómeno, David Walker lo considera como una economía politizada. Y para darnos una idea del perfil de los personajes que jugaban un papel significativo en la vida económica, nos dice Walker "el enpresario era al mismo tiempo comerciante, minero, hacendado, agiotista, político e industrial, o estaba relacionado con alguien que lo era". 30

Este tipo de estudios han servido como una llamada de atención para

29 En varios trabajos, Meyer desarrolla esta idea. Véase en particular: "Ingleses", 1987, pp. 57-72.

30 Walker, Parentesco, 1991, p. 45. no perder de vista ambos mundos en el posible análisis. La economía y la política, en este periodo histórico, se encontraban fusionadas y respondían a una lógica impuesta por los grupos de notables, que participaban a nivel nacional y/o regional. La anarquía, como se le ha llamado, era sólo el escenario donde actuaban los grandes especuladores, quienes se beneficiaron enormemente con las rentas del tesoro.

En este terreno, la crisis financiera obligó a los gobiernos independientes a buscar recursos y

permitió a los comerciantes, tanto nacionales como extranjeros, tener acceso a una nueva actividad económica que, por varios años, mostraría ser la más productiva de cuantas podían emprenderse en el país: los préstamos o negocios con el gobierno. ${ }^{31}$

O como dice Walker, era más fácil sacar plata de las arcas del Estado que de las minas.

La urgencia económica del erario provocó que los funcionarios pensaran la manera, no siempre la más inteligente, de allegarse recursos. Por esta razón, paulatinamente, las salinas arrendadas fueron cayendo en manos de los prestamistas por medio de las hipotecas. De todos los negocios de esta naturaleza, el que más llama la atención por su enorme voracidad, es el caso de Felipe Flores, quien hipotecó las salinas de Tehuantepec.

En febrero de 1839, "el supremo gobierno" recibió un préstamo de $\mathbf{8 0} 000$

${ }^{31}$ Meyer, "Quedaron" (inédito), p. 7. 
pesos, pagaderos a nueve años; en ese caso, el gobierno se comprometió a pagar 28800 pesos anuales de interés, lo que correspondía al $3 \%$ mensual. Además, se debían abonar 16000 pesos anuales al capital. Con el fin de garantizar el préstamo "se me hipotecarán las rentas nacionales y en especial las salinas de Tehuantepec, las cuales no podrán ser vendidas y arrendadas sin que proceda la liquidación". 32

Cabe subrayar que diversos estudios han analizado las tasas de interés que eran comunes o frecuentes en este tipo de transacciones. ${ }^{33}$ Walker afirma que la familia Martínez del Río prestaba al 1 o $2 \%$ mensual y dentro de la perspectiva de la familia, se consideraba un buen negocio todo aquel que produjera por lo menos el $15 \%$ anual. ${ }^{34}$ Los intereses cobrados por Felipe Flores rebasaban con mucho esos márgenes, con lo que en pocos años se duplicaba el monto de la deuda. Parece ser que las tasas extremadamente altas eran exclusivas de los negocios con el gobierno; sin embargo, este tipo de pautas iban en detrimento de los particulares, pues el mercado solía mantener tasas de interés muy elevadas.

Durante ese mismo año, en subasta pública, Manuel Escandón ofreció comprar al gobierno general "las playas y tequesquite de Sacualco y Sayula en el departamento de Jalisco por

\footnotetext{
32 Archivo de Notarías de la ciudad de México (AN): Notaría 717, Jiménez de Velasco, 20 febrero 1839.

33 Olveda afirma que durante las reformas borbónicas, las tasas de interés se elevaron del $3 \%$ al 5\%, Oligarquia, 1991, p. 70.

34 Walker, Parentesco, 1991, p. 50.
}

80000 pesos. Después de un regateo, los funcionarios lograron obtener 92000 pesos por la venta y le impusie. ron al comprador, la condición de que "no se alterara el precio que ha sido costumbre dar la sal a los mineros". 35

Más adelante, en 1842, el gobierno remató las salinas; los compradores fueron antiguos arrendadores, prestamistas y ex funcionarios públicos. El valor que se le dio a cada una de las propiedades se hizo con base en la renta que pagaban, considerando este monto como el 5 o $6 \%$ del valor total. Por ejemplo: las salinas de Soto la Marina y San Fernando en Tamaulipas se rentaban en 2229 pesos anualmente y, teniendo como base el $6 \%$, se cotizaron en 37 150. Pero el comprador, Ramón de la Garza, sólo pagó en efectivo el 46.5\%; el resto fueron créditos reconocidos por el gobierno, adeudos por salarios devengados y deducción del arrendamiento que se tenía adelantado.

Resulta inexplicable cómo el gobierno vendió las salinas, que poseían un recurso natural susceptible de ser explotado, de la misma manera y condiciones en las que se vendía cualquier otro tipo de bienes inmuebles. Para realizar dicha venta, los valuadores no tomaron en cuenta la explotación potencial de la sal, como se hacía en el caso de las ventas de las minas.

Los compradores de salinas pagaban una parte en efectivo, la menor posible, y el resto se cubría casi siempre con créditos reconocidos por el gobierno; dicha forma de pago fue la

35 AN: Notario 215, Miguel Díez de Bonilla, 20 febrero 1839. 
más frecuente y sólo tuvo pequeñas variaciones en relación con el tipo del comprador. Por ejemplo, el comerciante Domingo Rascón se interesó por comprar las salinas de Custodio, Chila, Olita, Zapotillo, Santispac, Valle de Banderas y Chamela. Para ello, propuso al gobierno entregarle 57000 pesos, porque en conjunto las salinas pagaban 4000 pesos de arrendamiento anual $y$, teniendo como base el 5\%, el avalúo ascendía a pagar $\mathbf{8 0} 000$ pesos. No obstante, Rascón ofrecía pagar sólo las dos terceras partes, es decir 57000 pesos; para cubrir esta suma, el comprador otorgaría una letra de 12000 pesos para cobrarse en Guadalajara, 3000 pesos en efectivo y 42000 en créditos reconocidos por el supremo gobierno.

Ante este seductor ofrecimiento, los funcionarios, magos de la economía, hicieron una nueva propuesta: pidieron a Rascón 38733 pesos por todas las salinas y para finiquitar la operación. Rascón se comprometió a pagar 15000 pesos en efectivo y poco más del $60 \%$ en créditos reconocidos por el gobierno. ${ }^{36}$

Resulta claro que el proceso de privatización de las salinas se prolongó por más de quince años. Durante este tiempo, transcurrieron tres etapas con diversas características: arrendamiento, hipoteca y venta. Por los ejemplos mencionados, podemos comprobar que los funcionarios públicos se sentaban a la mesa de negociaciones en una condición de desventaja. Por el contrario, los particu-

36 aN: Notaría 715, Ramón Villabobos, 18 octubre 1842 y 19 noviembre 1842 . lares se levantaban y guardaban en el bolsillo contratos redituables. El erario cobró rentas exiguas que no ayudaron a aliviar sus necesidades. El déficit presupuestal provocó que se cayera en brazos de los prestamistas, quienes aportaron su liquidez para llevarse una buena tajada.

Los contratos de venta de las salinas son un ejemplo palpable de la habilidad con que los grandes empresarios manejaban la deuda pública. Ellos adquirían créditos contra el gobierno a bajo precio y los revendían a un alto precio. En el caso de las salinas, los compradores utilizaron la deuda pública para pagar una buena parte de los bienes nacionales. De esta manera, las propiedades de la nación se privatizaron a cambio de unos cuantos pesos.

\section{IAGUNA DE INTRIGAS}

A finales de 1835, en la ciudad de San Luis Potosí, el gobierno general convocó públicamente al arrendamiento de las salinas de Peñón Blanco. Desde tiempo atrás, Antonio Esnaurrizar arrendaba los ricos yacimientos por 16000 pesos. En esa ocasión, las autoridades recibieron tres ofertas: de Vital Fernández, Joaquín Ma. Errazu y del propio arrendador. La comisión de almoneda, compuesta por el comisario de Hacienda, el juez del distrito y dos representantes del supremo gobierno, acordaron que la propuesta de Errazu era la más atractiva, quien ofreció pagar una renta anual de 18250 pesos. Años depués, la opinión pública se enteró de que Errazu había resultado elegido, por- 
que prometió a los funcionarios otorgar un préstamo gracioso y "este servicio fue causa de que se le prefiriese en la subasta".37

Las bases del contrato fijaron un arrendamiento por siete años y el gobierno concedió un año más como premio y sin costo para el arrendador. El precio de la sal fue fijado en tres reales por cada fanega de saltierra y ocho reales por cada fanega de sal blanca. El arrendatario debía pagar 250 pesos anuales por utilizar las fincas instaladas y los gastos de reparación correrían por su cuenta, sin esperar recompensa al finalizar el contrato. E1 arrendatario debía pagar las existencias almacenadas en un plazo de siete años; para amortizar dicha deuda, Errazu pagaría abonos anuales. Por una dádiva, el gobierno se comprometió a solventar los gaștos que generaba la limpieza de las lagunas.

El arrendamiento se firmó en un coyuntura política de enorme trascendencia. El presidente Antonio López de Santa Anna, al frente del ejército, se encontraba acantonado en San Luis Potosí por no contar con recursos suficientes para ir a sofocar la revuelta texana. Por esta razón, las bendiciones de Santa Anna hicieron que las condiciones del contrato se modificaran e inclinaran a favor del asentista.

En el nuevo arreglo, Errazu no concedió el prestamo gracioso prometidoo, pero anticipó 145000 pesos al gobierno como pago adelantado de las existencias almacenadas. La sal al-

37 Cayetano Rubio, "Salinas del Penón Blanco en el departamento de San Luis Potosín, El Siglo $X Z X$, alcance al núm. 460, 14 de enero de 1843.

LA SAL DE LAS FINANZAS macenada ascendía a 119632 pesos según los peritos valuadores. Pero por "el favor del préstamo rápido", Errazu recibió un descuento de más del $30 \%$ y pagó por toda la sal 89724 pesos. El resto de la operación, 55275 pesos, se destinó para pagar la renta de las salinas tres años por adelantado.

Joaquín María Errazu era un destacado empresario que residía en la ciudad de San Luis Potosí, pero sus negocios abarcaban un amplio territorio. Errazu mantenía una relación muy estrecha con los estados vecinos de Zacatecas y Querétaro. Además de ser comerciante, Errazu controlaba la fábrica y el monopolio de la pólvora en el estado de Zacatecas, negocio que lo vinculaba con el mundo minero, 38 aunque la familia se había dedicado al comercio del mercurio desde finales de la época colonial. Otra empresa que dirigió Errazu fue la línea de diligencias que recorría el camino de Querétaro a San Luis Potosí. 39

En 1840, Errazu participó como accionista del monopolio del tabaco; compartía las ganancias con otros empresarios de gran prestigio económico como: Cayetano Rubio, Manuel Escandón, Felipe Neri del Barrio, Benito Magua y Agüero González y Cía. Los intereses de Errazu representaban el $12.5 \%$ en este negocio. ${ }^{40}$ Podemos afirmar que Joaquín María Errazu, que nunca renunció a la nacionalidad española, tenía buena experiencia en las transacciones con el erario nacio-

${ }^{38}$ Representacion, 1840.

39 AN: Notaría 426, Francisco Madariaga, 28 de enero de 1846.

${ }_{40} \mathrm{AN}$ : Notaría 426, Francisco Madariaga, 4 de abril de 1840 . 
nal. La enorme liquidez de sus negocios y su relación familiar con Cayetano Rubio, fueron elementos indispensables para invertir en empresas protegidas, que representaban escaso riesgo y grandes utilidades.

A finales de 1838, el Congreso general, por iniciativa del ministro de Hacienda Pedro José Echeverría, autorizó al ejecutivo para vender las salinas de Peñón Blanco. El erario necesitaba recursos con gran urgencia y la venta se tenía que realizar en un plazo breve. De manera especial, el Congreso condicionó al comprador para que continuara vendiendo la sal a los mismos precios y plazos acostumbrados. 41

Por medio de pregones, el gobierno hizo pública la venta de las salinas en las ciudades de México y San Luis Potosí. En ese momento, no apareció ningún postor; aparentemente, el negocio no interesaba a los inversionistas. Después de algunos dias, Joaquín Ma. Errazu realizó una maniobra excepcional que le permitió asegurar la propiedad de las salinas de manera definitiva. Por la pobreza del erario, Errazu ofreció otorgar un préstamo al gobierno y pidió a cambio la hipoteca de las salinas.

En virtud de la escasez que sufre la hacienda pública y deseoso de aliviarla en alguna parte, decía Errazu, propongo al supremo gobierno, entregarle inmedia-

41 Ley 2000, "Autorización al gobierno para que enajene las salinas de Peñón Blanco, y el edificio de la ex inquisicion", 22 de noviembre de 1838. tamente la cantidad de 102000 pesos en dinero en efectivo. ${ }^{42}$

El préstamo se cubriría en un plazo de cuatro años y causaría el $1 \%$ de interés mensual; por tal motivo se hipotecarian las salinas de Peñón Blanco. Los intereses generados por el préstamo amortizarían el arrendamiento; otras cláusulas estipularon las garantías y beneficios del prestamista.

Algunos días después, Errazu concedió otro préstamo al gobierno por 50000 pesos pero, en esta ocasión, la cantidad entregada se hizo con base en una canasta de papeles de poco valor. Entre los documentos se encontra. ban letras de cambio, pagarés, créditos contra el gobierno, etcétera. Por este segundo préstamo, el gobierno se comprometió a pagar el interés del $1.5 \%$ mensual. 43

Las jugosas ganancias económicas y las duras condiciones de la hipoteca se convirtieron en una pieza clave para consolidar el negocio salinero de Errazu. El gobierno tenía que cubrir tantos requisitos para saldar su cuenta con el prestamista, que le era prácticamente imposible buscar o animar a otros inversionistas. Por medio de la hipoteca, el arrendador eliminó a todos los posibles competidores. E1 préstamo no sólo fue una medida para respaldar el contrato de arrendamiento, sino un mecanismo para hacer una oferta al gobierno y apropiarse definitivamente de las salinas. Sólo había que esperar el momento preciso.

12 an: Notaría 715, Ramón Villalobos, 4 de enero de 1839.

43 N: Notaría 715, Ramón Villalobos, 7 de enero de 1839. 


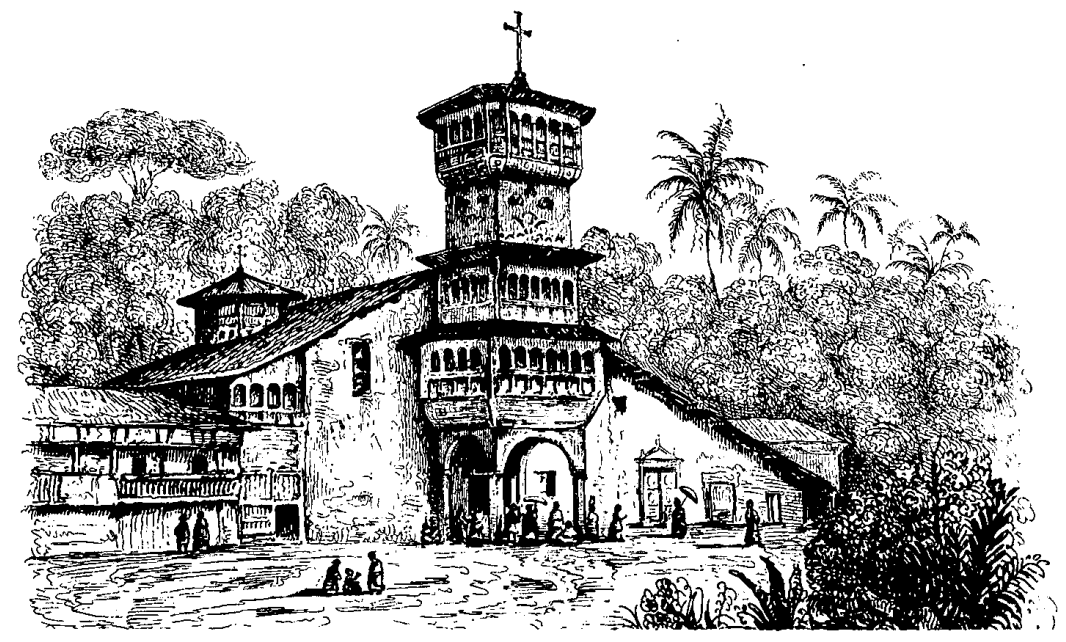

El empresario conocía el deterioro de las finanzas públicas y sabía que el gobierno no cumpliría con sus compromisos, aunque así lo deseara. Esta situación le brindó una gran seguridad al arrendador, quien realizó una cuantiosa inversión en equipo e instalaciones. En 1841, se iniciaron los trabajos para cambiar el sistema de explotación en las salinas. Tradicionalmente, la sal se había recogido en las orillas de las lagunas donde se formaba una costra. Con el fin de aumentar la productividad y la calidad de la sal, se construyeron pozos de extracción así como tanques de almacenamiento y secado. Este método obtuvo muy buenos resultados, con lo cual se transformó en poco tiempo el proceso productivo de las salinas.

Antes de que se cumpliera el plazo del contrato y se viera el gobierno obligado a reintegrar el dinero y réditos del préstamo, el presidente Santa Anna decidió sanear el negocio de las salinas, teniendo como apoyo "su natural viveza, luces y no comunes conocimientos en las ciencias financieras", como lo ensalzaría uno de los prestamistas. ${ }^{44}$

Esta coyuntura involucró a Cayetano Rubio, conocido especulador de probada experiencia en el manejo de las finanzas públicas, estrechamente ligado a las empresas y a la familia Errazu. En octubre de 1842, Rubio negoció con el presidente Santa Anna el contrato de compra-venta de las salinas. Rubio pagó 304176

41 Cayetano Rubio, "Salinas del Penón Blanco en el departamento de San Luis Potosín ${ }^{\prime}, E l$ Siglo XWX, alcance al núm. 460,14 de enero de 1843. 
pesos, los cuales correspondían al avalúo por la renta que se pagaba teniendo una base del 6\%. Don Cayetano, junto con Errazu, adquirió el compromiso de saldar las cuentas pendientes del gobierno, las cuales ascendían a 179837 pesos, por el monto de la deuda y réditos vencidos. Rubio entregó 5000 pesos en efectivo a la hacienda pública y además adquirió el compromiso de pagar 134329 en créditos reconocidos contra el erario en un plazo de ocho meses. Igualmente, para proteger los intereses del antiguo arrendador, Rubio adquirió el compromiso de pagar en efectivo y al contado el valor total de las existencias de sal. ${ }^{45}$

En el contrato de venta se estipuló que el gobierno cedía las salinas de Peñón Blanco

con todas sus anexas, terrenos, casas, trojes, lagunas y cuanto le pertenece y añadía que el comprador gozará de.los derecbos del fisco; y lo que estaba en sus atribuciones, que dan poder $y$ facultad necesaria para que sin necesidad de títulos por no haber algunos, tome posesión judicial o extrajudicial.

Es importante advertir que el contrato no determinó los límites de la propiedad que se vendía y mucho menos aclaro el hecho de ceder los dere. chos del fisco.

En poco tiempo, los mencionados vicios en el contrato provocaron que el comprador declarara haber adquirido el monopolio de la sal a nivel regional

45 AN: Notaría 715, Ramón Villalobos, 29 de octubre de 1842. e intentó incorporar a su propiedad todas las salinas conocidas y nuevas localizadas en una amplia región. 46

La Junta Departamental de San Luis Potosí levantó una fuerte protesta por los daños "irreparables" de la venta de las salinas; en una larga carta enviada al presidente Santa Anna, los miembros de la Junta solicitaron la anulación del contrato de compra-venta, argumentando: las irregularidades cometidas en el procedimiento de venta, el escaso beneficio que había reportado el negocio a la hacienda pública y la incapacidad del ejecutivo para llevar a cabo una empresa de tal naturaleza. Insistieron especialmente en que los ciudadanos de San Luis Potosí, en repetidas ocasiones, habían manifestado su desacuerdo por la "enajenación" de las salinas. La Junta Departamental intentaba proteger y preservar los recursos naturales para usufructo de los ciudadanos potosinos; consideraban que la venta de las salinas era una especie de violación a su soberanía. ${ }^{47}$

Ante esta protesta, el editorialista del periódico El Siglo XIX aprovechó la oportunidad y mostró su inconformidad por la política "de despojo" que varios estados habían sufrido. Aseguró que los contratos de arrendamiento y la venta de los bienes na. cionales iban en detrimento de los estados y del conjunto de la nación. El despojo de los recursos estatales no era más que el producto de las injustas

46 Las salinas de Peñón Blanco comprendían en un principio las lagunas de Santa Clara y la del Morro en Zacatecas. Pero Cayetano Rubio reclamó el derecho sobre veinte lagunas.

47 "Renta Nacional de Salinas", El Siglo XIX, 6 de enero de 1843 , p. 2 
decisiones del gobierno central. El periodista hizo un llamado general con el fin de que otras entidades apoyaran a San Luis Potosí para frenar la política del gobierno central e intentar la anulación del contrato de las salinas. ${ }^{48}$

La respuesta fue violenta. Cayetano Rubió narró en detalle la historia de las condiciones jurídicas y económicas de las salinas durante el arrendamiento de la familia Errazu; argumentó de manera amplia el contrato de compraventa con el gobierno e invitó a sus opositores a que invirtieran en la empresa.

Les cedo, decía, desde luego mis derechos de comprador y les doy las salinas en la misma cantidad 304166 pesos, 5 reales, 8 granos en que yo las he comprado, pagándome además las existencias a los propios precios y en iguales términos en que las recibí de Errazu, y como éste las recibió de su antecesor, y también los costos de todas las obras que se han construido para el nuevo beneficio de la evaporación. De esta manera, con poco más de 500000 pesos, podrán los nuevos empresarios recoger cada año un líquido producido de más de 124000 pesos, según sus calculos [de los opositores], quedando indemnizados en menos de cinco años. 49

Mientras tanto, las diputaciones de minería de los estados de San Luis Potosí y Zacatecas recibieron una lluvia

$-$

48 "Bienes Nacionales, Salinas del Peñón Blanco en el departamento de San Luis Potosí", El Siglo XIX, 6 enero 1843.

49 Cayetano Rubio, "Salinas del Penón Blanco en el departamento de San Luis Potosí", El Siglo XIX, alcance al núm. 460, 14 de enero de 1843. de denuncios de terrenos y vertientes de agua salada. En poco tiempo se generó una fiebre salina que atrajo a una multitud de personas, quienes exploraron minuciosamente la región en busca de sal. Para buena fortuna de muchos, los yacimientos salinos y las vertientes de agua salada se localizaban con relativa facilidad. La fiebre de la sal afectó a las haciendas vecinas de Peñón Blanco propiedad de la familia Pérez Gálvez, antiguos y poderosos mineros de Guanajuato. Además, Cayetano Rubio vio a los denunciantes como una grave amenaza para sus intereses monopólicos.

Esta situación desencadenó una guerra que adquirió distintos matices y se llevó a cabo en múltiples frentes, desde las piezas humildes de los juzgados locales hasta los perfumados salones de los ministerios; entre la oligarquía regional, los funcionarios públicos y los buscadores de sal.

Siguiendo las leyes mineras, las diputaciones de minería y los juzgados locales otorgaron posesión de los terrenos denunciados a muchos particulares; como en el caso de José Eusebio de Torres que descubrió unos terrenos salinos en la hacienda de Cruces. ${ }^{50} \mathrm{En}$ 1844, Torres inició los trabajos para beneficiar las vertientes de agua salada que había descubierto. La noticia corrió rápido y tanto Cayetano Rubio como Francisca Pérez Gálvez se dieron por enterados. Ambos utilizaron sus recursos para frenar los descubrimientos y trabajos en los yacimientos sali-

50 Suplemento al Boletín núm. 158, San Luis Potosí, 23 de abril de 1845. Firmado Eusebio de Torres. 
nos. En esta ocasión Cayetano Rubio reclamó al gobierno el derecho exclusivo de producir y comerciar la sal en la región. Por su parte, la señora Pérez Gálvez defendió el derecho inviolable a la propiedad.

Las autoridades locales apoyaron de manera velada a los denunciantes, mientras que en los altos círculos de la administración titubearon en dar una solución pronta al problema. Pero la influencia de los propietarios hizo posible que el ministro de Hacienda ordenara suspender todos los denuncios y trabajos de los salineros. Esta medida fue acompañada con la iniciativa de revisar el contrato de venta de las Salinas de Peñón Blanco por el Congreso general. ${ }^{51}$

La situación se volvió cada día más conflictiva, los mineros de Zacatecas, principales consumidores, alzaron su voz en contra del monopolio que pretendía ejercer Cayetano Rubio. Pero calmaron sus ánimos al saber que las condiciones del crédito y el precio de la sal se mantendrían sin alteración.

Después de la tempestad y con las aguas quietas, a principios de 1846 , Cayetano Rubio vendió a Joaquín María Errazu (su yerno) las salinas de Peñón Blanco por 150000 pesos de "plata del cuño corriente mexicano". De esta manera, Rubio otorgó todos los derechos de la propiedad y se retiró del negocio de la sal, para continuar con sus actividades comerciales y en la fábrica textil El Hércules de la ciudad de Querétaro. 52

51 Comunicados, s.f.

52 aN: Notaría 426, Francisco Madariaga, 10 de febrero de 1846 .
Cayetano Rubio tomó parte en la venta de Peñón Blanco como un intermediario eficaz. Tenía grandes influencias políticas y su relación con el presidente Santa Anna ayudó en mucho a la familia Errazu para que pudieran apropiarse de las salinas. Estos empresarios tuvieron una marcada preferencia por invertir en negocios protegidos por el Estado, los cuales rendian buenas ganancias. Como se ha mencionado, Joaquín María Errazu tenía inversiones considerables en los estancos de la pólvora, tabaco y salinas. Sin embargo, a diferencia de otros empresarios de la época, las ganancias obtenidas por Errazu fueron reinverti. das en la industria de la sal. Como sabemos, la dinastía Errazu conservó el pleno dominio de Peñón Blanco hasta 1906, cuando fue vendido a una empresa inglesa. ${ }^{53}$

Finalmente, por su ubicación geográfica, Peñón Blanco jugó un papel fundamental para abastecer a los centros mineros cercanos a San Luis Potosí, como por ejemplo Zacatecas, Aguascalientes y Guanajuato, entre otros. Los circuitos comerciales de la sal tendieron fuertes lazos de dependencia con la industria minera; por lo tanto, el mercado minero condicionó en buena medida el crecimiento o contracción de las salinas.

A mediados del siglo XIX, la producción minera tuvo un nuevo repunte; por esta causa, la industria salinera tuvo el crecimiento más grande• de su historia. Además, no podemos olvidar que Peñón Blanco abasteció a

53 Vease Rodríguez Barrera, "Apuntes", 1947, pp. 433-492. 
Apéndice I

Rentas de las salinas federales productos líquidos,

1825-1850

$\begin{array}{lllr}1825 & 29620 & 1839 & 102500 \\ 1825-26 & 44921 & 1840 & 9504 \\ 1826-27 & 63516 & 1841 & 43329 \\ 1827-28 & 49552 & 1842 & 630727 \\ 1829-30 & 65671 & 1843 & 50676 \\ 1830-31 & 66506 & 1844 & 48676 \\ 1833-34 & 45369 & 184849 & 2646 \\ 1835-36 & 82794 & 1849-50 & 365 \\ 1836-37 & 23645 & & \end{array}$

Nota: 1825 solo corresponde a los primeros ocho meses; $1825-26$ comprende diez meses; en el año económico de 1833-1834 no hay noticia de las salinas de Tamaulipas; el anoo económico de 1848-49 abarca 18 meses.

Fuente: Memorias de la Secretaria de Hacienda, 1825-1850.

Apéndice II

Precio de los distintos tipos de sal en la compañía minera zacatecano-mexicana, 1836-1844

$\begin{array}{cccccc}\text { Sal tierra } & \begin{array}{c}\text { Sal grano } \\ \text { (fanegas) }\end{array} & \begin{array}{c}\text { Sal comin } \\ \text { (carga) }\end{array} & \begin{array}{c}\text { Tequesquite } \\ \text { (fanega) }\end{array} & \begin{array}{c}\text { Temescuitate } \\ \text { carga }\end{array} \\ 1836 & 10 \mathrm{r} . & 3 \mathrm{p} . & & 6 \mathrm{p} . & 7 \mathrm{p} .4 \mathrm{r} . \\ 1837 & 11 \mathrm{r} . & 3 \mathrm{p} . & & 1 \mathrm{p} . & 7 \mathrm{p} .4 \mathrm{r} \\ 1838 & 11 \mathrm{r} . & 3 \mathrm{p} . & & 1 \mathrm{p} . & 7 \mathrm{p} .4 \mathrm{r} \\ 1839 & 10 \mathrm{r} . & 3 \mathrm{p} . & & 1 \mathrm{p} . & 7 \mathrm{p} .4 \mathrm{r} \\ 1840 & 10 \mathrm{r} . & 3 \mathrm{p} . & & 1 \mathrm{p} . & 7 \mathrm{p} .4 \mathrm{r} \\ 1841 & 10 \mathrm{r} . & & 10 \mathrm{p} . & 6 \mathrm{p} . & 7 \mathrm{p} .4 \mathrm{r} \\ 1842 & 14 \mathrm{r} . & & 8 \mathrm{p} . & 1 \mathrm{p} . & 7 \mathrm{p} .4 \mathrm{r} \\ 1843 & 14 \mathrm{r} . & & 6 \mathrm{p} . & 1 \mathrm{p} . & 7 \mathrm{p} .4 \mathrm{r} \\ 1844 & 14 \mathrm{r} . & & 4 \mathrm{p} . & 6 \mathrm{r} 3 \mathrm{gr} & 7 \mathrm{p} .4 \mathrm{r}\end{array}$

Nota: Los precios están dados en pesos (p.), reales (r.) y granos (gr.). 1 fanega $=90.8148$ ltr. y 1 carga $=181.62971$ tr.

Fuente: Informe 1845.

otros sectores económicos con necesidades más restringidas pero que ayudaron al desarrollo y consolidación de la industria salinera.
La inversión de capital fue un factor básico para conseguir enormes volúmenes de sal; el sistema productivo se transformó gracias a las nuevas 
técnicas que fueron incorporadas. Así, la explotación de las salinas dejó de ser una actividad dependiente de un ciclo estacional y se convirtió en una labor permanente. Esta situación estimuló a otros empresarios para que invirtieran en el negocio de la sal. Sin embargo, la libre concurrencia desarticuló las estructuras del mercado que, por tradición, había sido cautivo, y desencadenó una disputa por los terrenos salinos.

La privatización de las salinas federales tuvo un alto costo político pues provocó un fuerte conflicto de intereses entre las entidades y el gobierno central. En el enfrentamiento, los estados pretendieron romper las ataduras coloniales de la explotación salinera, con el fin de allegarse recursos fiscales y para mantener integra su soberanía. En cambio, el gobierno central insistio en conservar ciertos privilegios patrimoniales y se resistía a perder su influencia en el mercado salinero, como en el hecho de imponer el precio de la sal subvencionar a la industria minera y frenar la política de laissez-faire.

\section{BIBLIOgRAFía}

-Burkart, Joseph, "Memoria de la explotación de minas en el Distrito de Pachuca", Anales de la Minería Mexicana, México, 1861.

-Carreón, Luis, Curso de explotación de minas, Imprenta del Gobiemo del Estado, Pachuca, 1903.

-Coatsworth, John H., "La industria minera en el siglo XVII", Los orígenes del atraso, nueve ensayos de bistoria económica de México en los siglos XVIII y
XEX, Alianza Editorial, México, 1990 (Colección Raíces y Razones).

-Comunicados y documentos a que se refieren relativos al ruinoso contrato que la administración provisional del general Santa Anna celebró con don Cayetano Rubio sobre las salinas de Peñon Blanco y demás limítrofes del Departamento de San Luis Potosi, Aniceto Villagrana, Zacatecas, s. f.

-Dictamen de la comisión de sistema de Hacienda, del Congreso de la Federación Mexicana, sobre las obsertaciones que blzo una comistón del Congreso de Jalisco acerca del proyecto de clasificactón de rentas, Imprenta del Supremo Gobierno en Palacio, México, 1824.

-Ewald, Ursula, The mexican salt industry 1560-1980, Gustav Fisher Verlag, Nueva York, 1985.

-Flores Clair, Eduardo, y otros, Estadisticas mineras de México en el siglo XIX, Instituto Nacional de Antropología e Historia, México, 1985 (Cuadernos de Trabajo, 47).

-Fonseca, Fabián de y Carlos de Urrutia, Historia general de Real Hacienda, 6 vols., Imprenta de Vicente García Torres, México, 1845.

-Herrera, Inés, "En busca del Nuevo Almadén. Archivos, libros y revistas en los acervos californianos", Historias, núm 21 , abril-septiembre de 1988, pp. 159-178.

-Informe de la junta menor permanente de la Compañía de Minas Zacatecano-Mexicana, del estado de la negociación de Fresnillo, en el año de 1844, Imprenta de Vicente García Torres, 1845.

-Lida, Clara E., "Sobre la producción de sal en el siglo XvII: salinas de Peñón Blanco", Historia Mexicana, vol. XIV (4), núm. 56, abril-junio de 1965, pp. 680-690.

-Manifiesto de la administración $y$ progresos de los ramos de la Hacienda Federal Mexicana desde agosto de 1824 a diciembre de 1826, Imprenta del Supremo Gobierno, en Palacio, México, 1827. 
-Medina, Antonio de, Exposictón al So berano Congreso Mexicano sobre el estado de la Hactenda Pública, y conducta del ctudadano..., Imprenta del Águila dirigida por José Ximeno, México, 1835.

-Memorta del ramo de Hacienda Fede. ral... leída en la Cámara de Diputados el 13 de enero, $y$ en la de Senadores el 16 del mismo... año de 1826, Imprenta del Supremo Gobierno, México, 1826.

-Memoria de la Hacienda Federal.. presentada... el 22 de mayo de 1835, Imprenta del Águila dirigida por José Ximeno, México, 1835.

-Meyer, Rosa María, "Los ingleses en México, la casa Manning y Mackintosh (1824-1852)", Historias, núm. 16, eneromarzo de 1987, pp. 57-72. "Los que se quedaron: $\mathrm{em}$ presarios españoles después de la independencia", (inédito).

-Multhauf, Robert P., El legado de Neptuno. Historia de la sal común, Fondo de Cultura Económica, México, 1985.

Olveda, Jaime, La oligarquia de Guadalajara, Consejo Nacional para la Cultura y las Artes, México, 1991.

Ordenanzas de minería, comentartos $y$ legislación minera basta 1874, Consejo de Recursos Naturales no Renovables, México, 1961.

-Ramírez, Santiago, "Conferencias mineras", El Explorador Mexicano, núms. 159, 1876-1877.
-Randall, R. W., Real del Monte: una empresa minera británica en México, Fondo de Cultura Económica, México, 1977.

-Representación que varios mineros $y$ beneficiadores de metales de Guanajuato, dirigieron a la Excma. Junta departamental. A fin de que se sinva interponer su influjo con el supremo gobierno de la República, contra el monopolio de la pólvora, que pretende establecer Joaquín Maria Errazu, Imprenta de Juan E. Oñate, Guanajuato, 1840.

-Rodríguez Barragán, Nereo, "Apuntes para la historia y geografia de la ciudad de Salinas en el estado de San Luis Potosí", Boletín de la Sociedad Mexicana de Geografía y Estadística, vol. LXH, núm. 2, 1947, pp. 433-492.

-Sarabia, Maria Justina, "El estanco de la sal en Yucatán, 1591-1610", Anuario de Estudios Americanos, vol. XXXV, 1978, Sevilla, pp. 379-405.

-Ventura Beleña, Eusebio, Recopilación sumaria de todos los autos acordados de la Real Audencia y sala del crimen de esta Nueva España, prol. Ma. del Refugio González, UNAM, México, 1981.

-Walker, David W., Parentesco, negocios y política, la familia Martínez del Río en Méxtco, 1823-1867, Alianza Editorial, México, 1991. 


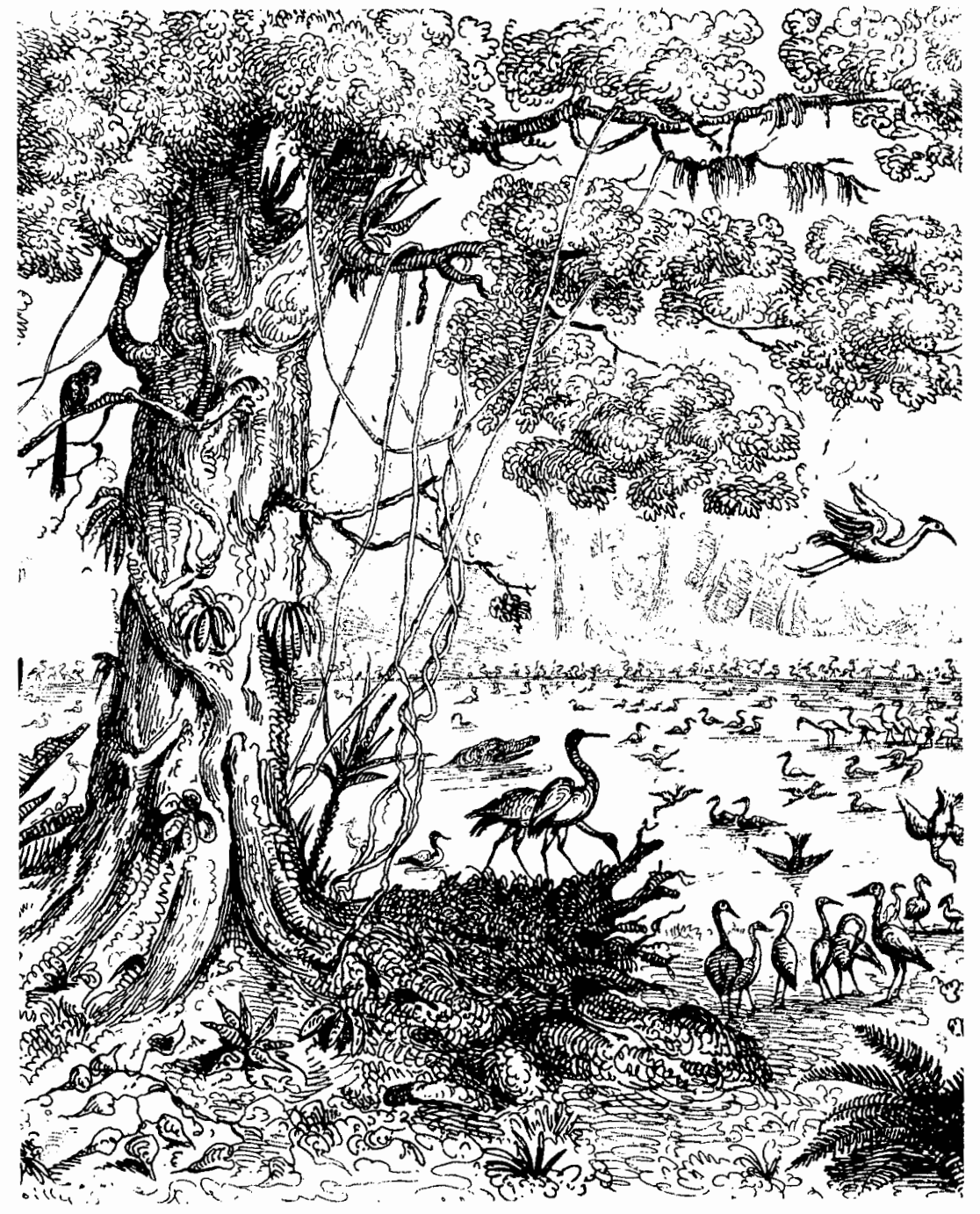

